\title{
3. DICTAMENES
}

\section{TASA SOBRE POSTES, CABLES, PALOMILLAS... QUE SE ESTABLEZCAN SOBRE LA VIA PUBLICA O VUELEN SOBRE LA MISMA: HECHO IMPONI- BLE. COMPETENCIAS. REPERCUSION}

352.72: 336.121

por

Fernando Malo

Profesor de Derecho Civil de la Universidad Autónoma de Madrid

SUMARIO: I. ANTECEDENTES.-II. CONSIDERACIONES: 1. EL HECHO IMPONIBLE. 2. LA VIA PÚBLICA. 3. APROVEC H AMIENTO ESPECIAL DE EMPRESA EXPLOTAdoRa DE SERVICIOS PÚblicos. 4. PaRTICULARIDADES DE LAS LINEAS ELÉCTRICAS DE ALTA TENSIÓN. 5. COMPETENCIA MUNICIPAL EN INSTALACIONES ELÉCTRICAS FUERA DEL CASCO URBANO.-III. LA REPERCUSION FISCAL.-IV. CONCLUSIONES.

\section{ANTECEDENTES}

1. La Eléctrica se dirige, el 23 de marzo de 1983, al suministrado comunicándole que en los recibos de facturación por sumi. nistro de energía eléctrica a la factoría de la Sociedad, la tarifa se incrementará en una cifra equivalente al pago que han efectuado al Ayuntamiento en concepto de liquidación de la tasa por ocupación del vuelo, suelo y subsuelo de la vía pública.

2. Con la comunicación se adjunta el Acuerdo a que han llegado la Sociedad suministradora de energía y el Ayuntamiento el día 17 de noviembre de 1982, mediante el cual la Eléctrica, por la 
citada tasa, reconoce adeudar al Ayuntamiento cantidades por los suministros efectuados en determinadas fechas y como resultado de la aplicación del 1,5 a los ingresos brutos obtenidos por la suministradora en ese período, estableciéndose una modalidad de pago de la cantidad desde el momento de la firma del contrato hasta finalizar veinte trimestres consecutivos.

3. También se pactan los ingresos del Ayuntamiento por la tasa durante los próximos cinco años $(83,84,85,86$ y 87), quedando fijados en varios millones de pesetas anuales.

4. La carta expresa que esos pagos corresponde efectuarlos al usuario, conforme a lo dispuesto en el Real Decreto 2385/81, de 20 de agosto, según el cual: "Salvo en el caso de que en la tarifa de aplicación se haga constar lo contrario, los tributos del Estado, Comunidades Autónomas, Provincias y Corporaciones locales establecidos sobre las instalaciones, suministro de energía y consumo son de cuenta del consumidor y su importe se incrementará al de las tarifas aplicadas".

5. El Ayuntamiento manifiesta en el contrato que «tiene aprobada desde el año 1977 la Ordenanza Fiscal que regula la tasa sobre postes, palomillas, etc., en su forma de participación en los ingresos brutos obtenidos por la Empresa suministradora de energía eléctrica en dicho término municipal».

Se trata de saber si el suministrado debe aceptar la repercusión de la tasa o si, por el contrario, puede negarse a pagar el incremento que se ocasione en el precio por la improcedencia de la repercusión o la ilegalidad de la misma tasa. Para ello vamos a examinar la validez de los fundamentos sobre los que se liquida la tasa y la fuerza de obligar de la repercusión.

\section{CONSIDERACIONES}

1. EL HECHO IMPONIBLE

El hecho imponible de la tasa viene determinado por el conjunto de circunstancias siguientes:

A) El aprovechamiento especial por la Empresa explotadora de servicios públicos de bienes o instalaciones de uso público municipal, participando el Ayuntamiento en los ingresos brutos. 
B) Que el aprovechamiento especial tenga lugar utilizando rieles, postes, cables, palomillas, cajas de amarre, de distribución o de registro, básculas, aparatos para venta automática y otros análogos.

C) Que esos elementos con los que se aprovechan los bienes o instalaciones de uso público municipal, se establezcan sobre la vía pública o vuelen sobre la misma.

De este modo queda configurado el acontecimiento fijado por la norma cuya realización origina la obligación de pago.

Interesa ahora examinar si se cumplen estos requisitos, es decir, si el paso de la energía eléctrica por el Municipio se ajusta a las circunstancias señaladas.

\section{LA VÍA PÚBLICA}

Observamos que los cables no. cruzan ninguna vía pública, ni los otros elementos o instalaciones que se citan en la tasa se apoyan en fachadas o edificios del pueblo.

La tasa se numera como la 15-11, aludiendo al artículo 15 del Real Decreto de 30 de diciembre de 1976 y al punto 11 del precepto. Ahí aparece la mención de vía pública, cuyo concepto podemos deducir del punto 11 en relación con otros del mismo artículo. Así, se habla de los «rieles, postes, cables, palomillas, cajas de amarre, de distribución o de registro, básculas, aparatos para venta automática y otros análogos que se establezcan sobre la vía pública o vuelen sobre la misma" en el punto 11 , que se refiere a los cables o instalaciones que vuelan o se colocan en las calles; en el punto 14 se habla de "quioscos en la vía pública»; en el 6 se gravan la «apertura de calicatas o zanjas en terrenos de uso público y cualquier remoción del pavimento o las aceras en la vía pública»; en el 9, "rejas de pisos, lucernarios, respiraderos, puertas de entrada, bocas de carga o elementos análogos en el pavimento o acerado de la vía pública...", de donde se deduce el pensamiento del legislador de que la vía pública está compuesta por dos zonas diferentes: el pavimento y el acerado.

El artículo 67 del mismo Real Decreto, dentro de la sección 3.", referida al impuesto de radicación, dice, en el punto 1 , que la cuota se determinará «... en función de la categoría de la vía pública en que se encuentre ubicado el local», y en el punto 3, "a efectos de los 
números anteriores, el número de categorías de calles no podrá exceder de...", con lo que se advierte la radical sinonimia entre «calle» y "vía pública», confirmada por el número siguiente del mismo artículo, que vuelve a referirse a «... locales que tengan fachada a dos o más vías públicas clasificadas de distinta categoría".

La vía pública, por tanto, es la calle $y$, además, no puede ser otra cosa que la calle tal como aparece liquidada la tasa.

\section{APROVEChAMIENTO ESPECIAL DE EMPRESA EXPLOTADORA DE SERVICIOS PÚbLICOS}

En efecto, la liquidación se practica en base a los ingresos brutos obtenidos por la Empresa suministradora de energía eléctrica mediante los aprovechamientos especiales constituidos en el suelo o vuelo de la vía pública.

El artículo 18 del Real Decreto de 30 de diciembre de 1976 autoriza a los Ayuntamientos para que la Ordenanza Fiscal correspondiente establezca la posibilidad de concertar con las Empresas explotadoras de servicios que afecten a la generalidad o una parte importante del vecindario, la cantidad a satisfacer por los aprovechamientos especiales. Además, el mismo artículo dice que el valor medio de los aprovechamientos se determinará reglamentariamente, y en cumplimiento de este mandato, el número $1 .^{\circ}, 1$, de la Orden de 31 de mayo de 1977 dice que: «En las tasas por utilización privativa o aprovechamientos especiales constituidos en el suelo, subsuelo o vuelo de la vía pública municipal en favor de Empresas explotadoras de servicios que afecten a la generalidad o parte del vecindario, y a los efectos del artículo 18 de las normas aprobadas por el Real Decreto 3250/1976, de 30 de diciembre, el valor medio del aprovechamiento podrá establecerse provisionalmente en el 1,50 por 100, como máximo, de los ingresos brutos que obtengan dichas Empresas dentro del término municipal».

Pues bien, el acuerdo se celebra con la Sociedad suministradora de energía, diciendo expresamente el Ayuntamiento en la manifestación primera del contrato, que regula la tasa «... en su forma de participación en los ingresos brutos obtenidos por la Empresa suministradora» de energía eléctrica en dicho término municipal, y aplica el 1,50 por 100 de los ingresos brutos obtenidos por la Empresa suministradora dentro del término municipal. 
Decía antes que la vía pública no puede ser más que la calle porque la tasa, tal como se ha aprobado y aplicado, está pensada para las Empresas explotadoras de servicios públicos que afecten a la generalidad o a una parte importante del vecindario, como señala el artículo 18 del Real Decreto del 76 y el artículo 448 (derogado) de la Ley de Régimen local, del que se toma la expresión concreta de "forma de participación del Ayuntamiento en los ingresos brutos». Servicios públicos como los teléfonos, el gas, el agua, la electricidad, implican ocupaciones permanentes del suelo o el vuelo, por lo que resulta difícil concebir una prestación de estos servicios sin usar las vías públicas. La justificación de la tasa en estos supuestos está muy clara: es la propia aglomeración urbana la que provoca el beneficio del suministrador, de manera que resulta razonable que el Municipio como tal detraiga una parte de esos beneficios.

De algún modo, los Ayuntamientos favorecen los fines económicos de las Empresas explotadoras, por lo que es justo que participen en el beneficio que las Empresas extraen del hecho urbano.

El Proyecto de Exacciones de 1918, en su artículo 19, reguló las tasas en participación, así como el Estatuto municipal de 1924, en su artículo 378, que sirvió de modelo al derogado 448 de la Ley de Régimen local. Ahora se vuelve a posibilitar el acuerdo en el artículo 18 del Real Decreto de 1976, pero no se menciona como forma de participación del Ayuntamiento en los ingresos brutos, sino meramente como concierto.

Pues bien, mediante tales aprovechamientos, las Empresas realizan la distribución y el suministro del servicio que constituye su explotación, por lo que el aprovechamiento de bienes e instalaciones municipales va íntimamente unido al hecho de la explotación económica de los mismos por las Empresas, proporcionando el Ayuntamiento a éstas los elementos necesarios para el desenvolvimiento de su negocio. Vista la relación de reciprocidad entre las prestaciones de Ayuntamiento y Empresa suministradora, la participación o la cifra concertada de la tasa supone el precio del aprovechamiento especial cedido.

Antes de seguir adelante conviene recordar que el suministro a las factorías es de $410 \mathrm{kv}$., es decir, que se efectúa a través de líneas de alta tensión, que ni pueden cruzar zonas urbanas ni esa energía es susceptible de aprovechamiento por la generalidad o parte importante del vecindario (art. 18, Real Decreto 1976) en la for- 
ma en que se recibe por el suministrado. De ello se deduce que la Empresa suministradora no realiza un servicio público al Municipio, sino que transporta la energia hasta una subestación de las Empresas suministradas, las cuales la utilizan integramente en su proceso industrial. Si la Eléctrica no aprovecha bienes e instalaciones municipales en la explotación del servicio público de suministro de energía eléctrica, no se ve el título por el que el Ayuntamiento exige la tasa por aprovechamientos especiales en la forma pactada que autoriza el artículo 18 para el supuesto de Empresas explotadoras de servicios públicos. El precio de la tasa lo pagarian las suministradoras a cambio de nada.

En cuanto al requisito de que los servicios que presten las Empresas explotadoras afecten a la generalidad o parte del vecindario, debemos tener en cuenta que esa Sociedad no es explotadora del servicio público de electricidad del Municipio con esas líneas, cables, postes y otros elementos, además de que los mismos conducen o soportan una forma de energía no susceptible de aprovechamiento por el Municipio.

La situación base de la imposición consiste en la ocupación del suelo, vuelo o subsuelo de la vía pública para la prestación del servicio público de energía eléctrica en el Municipio y que afecte a la generalidad del vecindario o a una parte considerable del mismo.

Es innumerable la jurisprudencia que se puede aportar para apoyar una interpretación estricta del supuesto. Bástenos recoger el principio establecido en el artículo 24,1 , de la Ley General Tributaria, cuando advierte que: "No se admitirá la analogía para extender más allá de sus términos estrictos el ámbito del hecho imponible o el de las bonificaciones». Por tanto, el concepto de vía pública, la condición nexal entre la persona obligada al pago y el suministrado, la ajenidad del Municipio respecto de la relación y la consideración del elemento subjetivo del destinatario del servicio, que es citado en la norma como punto de conexión del servicio público que atañe a una generalidad o parte importante del vecindario, deben considerarse en sus términos estrictos, sin tolerar extensiones que violentarían el hecho imponible tal como ha sido diseñado por el legislador. 


\section{Particularidades de las líneas eléctricas de alta tensión}

El artículo 6. de la Ley de 18 de marzo de 1966 dispone que «no podrá imponerse servidumbre de paso para las líneas de alta tensión sobre edificios y sus patios y corrales, sobre los centros escolares y campos deportivos cerrados y los jardines y huertos, también cerrados, que se hallen anejos a las viviendas, siempre que la extensión de tales huertos y jardines sea inferior a media hectárea".

Hay otras limitaciones establecidas en el artículo $6 .^{\circ}$ de la Ley y en el 26 de su Reglamento de 20 de octubre de 1966, pero no parece que esta cuestión pueda ofrecer dificultades en relación con zonas pobladas, y menos en el interior de poblaciones, pues la prohibición antes indicada haría jurídicamente imposible un tendido aéreo de líneas eléctricas de alta tensión en tales zonas. Claro está que las líneas atraviesan el término municipal, pero éste aparece como el ámbito en que han de producirse los ingresos brutos de las Empresas explotadoras de los servicios públicos, es decir, como el elemento espacial de la base imponible, no del hecho tributario, que sólo sujeta a las Empresas de esa clase que utilizan privativa - especialmente el vuelo sobre la vía pública mediante la colocación de rieles, postes, cables o palomillas.

A quien esté sujeto se le liquidará la tasa considerando todos los ingresos que obtenga dentro del término municipal.

Queremos dejar constancia de que la Ordenanza no distingue entre alta y baja tensión, y siendo la norma aplicable, donde no distingue, no se debe distinguir, según el viejo aforismo romano. Lo que sucede es que, aparte de no afectar el hecho imponible a la Empresa suministradora, resulta impensable que el mecanismo de exacción de tributos a las Empresas explotadoras de servicios públicos municipales por el vuelo sobre la vía pública con postes, cables y palomillas, pueda ser utilizado también para gravar el transporte de la energía eléctrica que cruza terrenos municipales con una línea de $410 \mathrm{kv}$. destinada a una subestación, de donde se pasa a cubas en las que se efectúa un proceso industrial específico.

\section{COMPETENCIA MUNICIPAL EN INSTALACIONES ELÉCTRICAS} FUERA DEL CASCO URBANO

Este enfoque nos lleva a cuestionar la competencia municipal en materia de instalaciones eléctricas fuera de la zona urbana del Municipio. Y así, el punto 3 del artículo $2 .^{\circ}$ de la Ley de 18 de marzo 
de 1966 reconoce la superposición de competencias de los Organos de la Administración del Estado y los Organos municipales, diciendo que «lo dispuesto en los párrafos anteriores se entiende sin perjuicio de la competencia que corresponde al Consejo de Ministros en virtud de esta Ley; de la que concierne al Ministerio de Obras Públicas en los aprovechamientos a que se refiere el párrafo 2 del artículo precedente, y de la propia de los Ayuntamientos cuando las instalaciones mencionadas se hayan de establecer en el interior de las poblaciones o en zonas de ensanche y reserva urbana».

Esta norma resulta claramente complementada con la establecida en el artículo 13 de la misma Ley: "Cuando las instalaciones eléctricas hayan de establecerse en el interior de las poblaciones o en sus zonas de ensanche ya aprobadas, la determinación de la forma y condiciones a que habrán de acomodarse aquéllas será competencia de los Ayuntamientos respectivos, sin perjuicio de la que corresponde a los Ministerios de Industria y de Obras Públicas, de conformidad con el artículo segundo de esta Ley y demás disposiciones aplicables. En estos casos se dará cumplimiento a las Ordenanzas municipales y Planes de Ordenación Urbana correspondientes".

El Reglamento de la Ley, de 20 de octubre de 1966, alude también a las competencias en el artículo $60^{\circ}$, y el Decreto de la misma fecha, que regula el otorgamiento de autorización administrativa en materia de instalaciones eléctricas, señala en el punto 2 del artículo $6 .^{\circ}$ que «igualmente, cuando las instalaciones eléctricas hayan de establecerse en el interior de las poblaciones, zonas de ensanche y de reserva urbana con planes de urbanización legalmente aprobados, se observará lo establecido en las Ordenanzas generales y locales de policía urbana».

En el mismo sentido, el artículo 15 de la citada disposición.

Todos estos preceptos «reconocen la competencia municipal, aunque referida al territorio urbano y no a la totalidad del término municipal. Si de esta legislación específica pasamos a la legislación local, no es menester acudir a la fórmula del artículo 101 de la Ley de Régimen local para encontrar atribuida a los Ayuntamientos competencia en esta materia, superpuesta a la estatal, pues el Reglamento de Obras municipales del 14 de julio de 1924, con una vigencia que no puede ponerse en duda, según es forzoso convenir al dictado de la transitoria 11 de aquella Ley, en tanto no se oponga 
a ésta, bien claramente define esta competencia, cual es de ver si se consultan los artículos 80 y siguientes; conjunto normativo del que infiere que respecto al territorio urbano (suelo urbano y reserva urbana; art. 62 y sigs. de la Ley del Suelo) tiene competencia el Municipio en materia de instalaciones eléctricas» (Sentencia de 29 de mayo de 1972).

Interesa recoger del artículo 81 del Reglamento citado que «en ningún caso se permitirá que las líneas aéreas de conducción de energía media o alta se establezcan a lo largo de vías públicas municipales, debiendo adoptarse, cuando sea indispensable cruzarlas, medidas de seguridad...».

Decíamos que la diversidad de fines de las instalaciones de servicio público del pueblo y las del complejo industrial, denotada por diferencia en kilovatios, ponía de manifiesto la ausencia de un interés municipal específico que pudiera justificar su competencia. El rodeo por el concepto de término municipal para atraer la competencia resulta vano ante la claridad de la Ley.

La misma interpretación del Tribunal Supremo distingue lo propiamente municipal de lo que le es radicalmente ajeno.

En cuanto al reflejo que la reforma de la Ley del Suelo puede tener en nuestro planteamiento, al carecer el Ayuntamiento de Plan General municipal, resulta de aplicación el artículo 66, que clasifica el territorio en suelo urbano y suelo no urbanizable, y dados los requisitos que exige el artículo 63 para calificar al suelo de urbano, debemos entender que el territorio por el que atraviesan las líneas de energía eléctrica de alta tensión que se dirigen a las factorías es suelo no urbanizable, el cual es equiparable al antiguo concepto de suelo rústico.

El resultado de esta argumentación lo podemos conectar con los criterios del Ordenamiento jurídico administrativo en materia de competencia, de modo que habrá de considerarse primordial lo dispuesto en el artículo 101 de la Ley de Régimen local cuando dice que «es de la competencia municipal el gobierno y administración de los intereses peculiares de los pueblos», que se dirigirá a la consecución de los fines que en el mismo artículo se expresan. La larga enumeración de fines u objetivos, extendida aún más con la fórmula abierta del apartado $\mathrm{K}$ de ese artículo, se encuentra limitada por la interpretación doctrinal y jurisprudencial de que es el «interés local» el que legitima una actuación municipal posible, y por la 
idea de la que la coordinación de las competencias estatales y municipales debe estar imbuida del criterio de «la manifestabilidad o evidenciabilidad", queriéndose con ello significar que lo razonable y sensiblemente valorado como estatal sea regulado por los órganos de esa competencia, mientras que lo que aparezca peculiar, específico y propio de la comunidad urbana municipal, como lo referente a servicios públicos municipales, sea dejado a la competencia de los Ayuntamientos.

Está muy clara en la Base $8 .^{a}$ de la Ley de 19 de noviembre de 1975, de Bases del Estatuto de Régimen local, esta misma filosofía, al referirse a la competencia municipal: en efecto, aunque el punto 1 de la Base extiende la capacidad de los Municipios a la «satisfacción de las necesidades generales y de las aspiraciones ideales de la comunidad municipal», el punto 3 dice que «los Municipios, dentro de su competencia, dedicarán una atención preferente a las materias siguientes... abastecimientos de agua y demás suministros públicos...», al lado de otras materias típicamente municipales, como la policía municipal, la ordenación del territorio, el saneamiento, el medio ambiente, los cementerios, etc.

Estas o parecidas consideraciones han llevado al legislador a excluir al Municipio de competencias en materia de líneas eléctricas de media y alta tensión que cruzan el terreno rústico de los pueblos, porque obviamente desborda el marco de los intereses peculiares de la comunidad urbana.

Recordemos, finalmente, que la tasa recae sobre las instalaciones, no sobre el suministro, de modo que el hecho imponible tiene entre sus componentes el de recaer sobre instalaciones que la Empresa coloca para realizar el suministro.

\section{LA REPERCUSION FISCAL}

En virtud de lo dispuesto en la condición 32 de las condiciones de carácter general del modelo de póliza de abono para el suministro de electricidad, que figura como anexo al Real Decreto de 20 de agosto de 1981, "los tributos del Estado, Comunidades Autónomas, Provincias y Corporaciones locales establecidos sobre las instalaciones, suministro de energía y consumo son de cuenta del consumidor, y su importe se incrementará al de las tarifas aplicadas». El alcance de esta disposición es ya escaso. No estando sujeta 
la Sociedad suministradora, tampoco lo estará el destinatario de la energía o consumidor final de la misma.

Cautelarmente, consideramos que se han violado dos principios tributarios esenciales por la forma en que se ha realizado el pacto. Por una parte, no ha sido tenida en cuenta la capacidad económica del consumidor final. Una cosa es que la Eléctrica sea la que comparece ante la Administración tributaria y resulte obligada al cumplimiento de las prestaciones formales y materiales del tributo, y otra diferente que conociendo el suministrador la realidad de que las Sociedades suministradas eran las únicas consumidoras en unas cuantías verdaderamente extraordinarias, haya omitido su llamamiento a intervenir en los pactos celebrados con la administración tributaria municipal.

El principio de la capacidad económica, criterio recurrente de todas las normas, ha sido desconocido. Su violación no puede considerarse justificada por el silencio de unas condiciones generales que desconocen el deber de colaboración jurídica entre dos entidades de primer rango, que operan con magnitudes económicas enormes. El deber de buena fe en las relaciones reciprocas obliga a ejecutar una conducta diferente, más ajustada a los principios jurídicos citados, sobre todo teniendo en cuenta que la norma que hace recaer la carga tributaria sobre el consumidor es de agosto de 1981, y el pacto es de 1982.

$\mathrm{Y}$ al no contemplarse la capacidad económica del consumidor al cuantificar el importe de la tasa, se viola el principio de igualdad ante la Ley establecido en la Constitución (art. 14), pues se discrimina al industrial, haciéndolo sin justificación objetiva y razonable (sentencia del Tribunal Constitucional de 10 de julio de 1981), de peor condición que a la Eléctrica, ya que ésta es protegida directamente por el Ordenamiento jurídico, y se le dan medios para ejercitar su derecho, mientras que el contribuyente se ve impedido de defenderse con arreglo a un principio esencial en el reparto de la carga tributaria.

El carácter inmediatamente aplicable de las normas constitucionales que contemplan derechos de la persona, nos obliga a afirmar la ilegalidad del acuerdo. 


\section{CONCLUSIONES}

1. La Eléctrica no está sujeta al hecho imponible contemplado por la tasa.

2. El Ayuntamiento no tiene competencia para imponer la tasa en la forma en que ha sido establecida y liquidada.

3. El pacto entre el Ayuntamiento y la Eléctrica es ilegal al violar frente al contribuyente principios jurídicos constitucionales directamente aplicables. 